\section{A CASE OF DYSECDYSIS IN A RETICULATED PYTHON, PYTHON RETICULATUS}

\author{
I. Nath ${ }^{1}$, V.S.C. Bose ${ }^{2}$, S.K. Panda ${ }^{3}$ and A.T. Rao ${ }^{4}$ \\ ${ }^{1}$ Assistant Professor, ${ }^{2}$ Associate Professor and Head, Surgery \\ Department, ${ }^{3}$ Assistant Professor, ${ }^{4}$ Emeritus Scientist, Pathology \\ Department, \\ Orissa Veterinary College, Bhubaneshwar, Orissa 751003, India
}

The loss of outer layers of the skin in reptiles is known as shedding or ecdysis, which is under hormonal control (Cooper, 1986). Usually the skin has a dull, matte appearance prior to shedding. In snakes shedding is preceded by an opacity and sometimes distension of the "spectacles" over the eyes with bluish colouration due to lymph intrusion between the layers of keratinised cells (Fowler, 1985). Dysecdysis is difficulty in shedding, which may occur due to adverse environmental factors like suboptimal temperature, relative humidity, ill health, dehydration, malnutrition, dermatitis or hormonal disturbances. The present paper describes a case of dysecdysis in a Reticulated Python (Python reticulatus).

\section{Case history}

At Nandankanan Zoo a 14-year old female Reticulated Python developed multiple injuries on its back and neck region. The wounds caused by the wire net enclosure were treated by the zoo doctor with povidone-iodine spray four times daily for 15 days with no improvement. The python was reported to be offfeed since two months. It was decided to put subcuticular sutures to the large gaping wounds.

\section{Treatment}

The python was grasped by its neck just behind the head by its handler. Then four helpers took firm hold along the length of the snake's body to avoid possible body constriction. The wounds were washed thoroughly with normal saline. It was observed that the snake was in the stage of ecdysis with dull. matte or mottled appearance of skin and "spectacle" blue eyes. The lateral side of the neck had a large open wound. Subcuticular sutures were applied using No.1 chromic catgut to the wounds. Povidone-iodine spray was continued for two weeks. The python did not accept live-baits of chicken till the end. Gunny bags soaked in lukewarm water were placed over the python for two weeks. The wounds healed in a month but the python died after two months.
In the present case the python might have sustained multiple injuries while crawling across the wire net enclosure to facilitate shedding. Ecdysis or shedding of skin occurs in most reptiles two to four times a year. During ecdysis snakes use hard objects in order to loosen the skin and the underlying new skin is soft and vulnerable to damage (Cooper, 1986). Apposition sutures to large gaping wounds with No.1 chromic catgut resulted in proper healing. Soaking the python's body with lukewarm water by means of gunny bags as suggested by Cooper (1986) was not successful in helping shedding. Forcible removal of eye cap was not undertaken to prevent injury to underlying spectacle and cornea. The cause for dysecdysis in this case may be due to injuries and inanition as evidenced by the rejection of the live-baits of chicken which it normally feeds in healthy condition.

On post mortem examination it was observed that the stomach and intestine were empty. Pleural cavity was filled with scanty bluish coloured fluid. The lungs were mildly congested. The muscles were pale. Heart muscles also revealed paleness with empty chambers. Pale and white patches were observed in liver and spleen. There was complete union of muscle layers at wound edges. The death of the python was attributed to anaemia and inanition during the prolonged period of the process of shedding.

\section{Acknowledgement}

The authors are thankful to the Director, Nandankanan Zoo for the cooperation extended.

\section{References}

Cooper, J.E. (1986). Reptiles: Physiology, pp.132-135. In: Fowler, M.E. (Editor). Zoo and Wild Animal Medicine. $2^{\text {nd }}$ edition. W.B. Saunders Company, Philadelphia.

Fowler, M.E. (1985). Surgical Principles and Techniques in Nondomestic Animals, pp. 1080 -1081. In: Gourley, I.M. and P.B. Vasseur (Editors). General Small Animal Surgery. $1^{\text {st }}$ edition. J.B. Lippincott Company, Philadelphia. 